\title{
The Linguistic Effects of Peer Editing as a Technique in Improving Collegiate Compositions
}

\section{MYLA L. SANTOS*}

\begin{abstract}
This study aimed to analyze the linguistic effects of peer editing in improving student's composition. Specifically, it described the revision priorities, types and extent of revision in peer editing. 50 students from two sections of Teacher Education programs at the College of Education, Central Luzon State University were randomly selected as participants. Descriptive - inferential research method was used. Results show that nouns and verbs were edited the most, and frequent revisions were substitution and deletion, and distribution and addition for first draft and second draft respectively. Data also show the employed functions of revision were grammatical and explicature, and the size of revision was at sentence level. T-test results show that peer editing was highly significant in over-all quality and in number of words. Because of the freer atmosphere of peer editing, students were not inhibited by the impositions of corrections, hence they developed empowerment and self-efficacy.
\end{abstract}

Keywords

Communicative language learning principle, errors, peer editing

- Faculty of College of Education, Central Luzon State University, the Philippines; myla santos@,clsu.edu.ph 


\section{IRJE | Indonesian Research Journal in Education | | Vol. 5 | No. 1|June | Year 2021|}

\section{Introduction}

Generally, students' language proficiency is assessed by the number of mistakes the students commit as they attempt to use the target language (TL). This is true specifically in their written output. Teachers are inclined to think that the less mistakes a student has in his/her lines, the better his/her language acquisition; otherwise, he/she has difficulty in using and mastering the features of the target language, or worse, he/she is not learning at all. However, the quality and frequency of the learner's errors are to be dealt with as available input for teaching and learning intervention. According to Selinker and Candlin (1992), errors are evidences that learners are internalizing and exploring the target language. It is undoubtedly the act of composing and improving which can create problems for students, especially for those writing in second language (L2) in academic context. Formulating new ideas can be very difficult because it involves transforming or reworking information. It is important, therefore, that those involved in the teaching of writing recognize these errors, then correct them; thus the need for editing and proofreading.

Several research prove that second language (L2) writing instruction depends crucially on writing evaluation or revision as that of Williams (2012), Bitchener and Ferris (2012), and Nelson and Carlson (2006). Feedback on writing quality determines proficiency level. As interpreted by students and teachers, when there is less correction on a paper, the writer of such has better proficiency than those with more feedback in the form of correction. More so, after the feedback, if the student writer is able to follow and attend to the feedback appropriately, it signifies a better proficiency than those who have inadequate attention to and action on the feedback. This provides instructional variation towards attainment of expected written output. Various research as that of Leki (1991), Sheen (2010) and Patridge (2014) argue that evaluation judgment is an integral part of the writing process particularly in the editing stages. The response made toward the writing process is closely associated to the strategies of editing. This can either be planned as pedagogical intervention which aimed at enabling students to improve their compositions.

However, experts recommend the exploration of the relationship between editing and text improvement. Text editing is clearly what really happens to the text, generally on surface changes. Text improvement is a concept of an objective sense, maintaining the opportunity to discover personal meaning. Yet, experts claim that the final assessment of any editing depends whether the editing process improve the text. The response made to the writing process is closely associated to the strategies of editing. This can be a planned pedagogical intervention which aimed at enabling students to improve their composition.

With this, it is believed that direct intervention may affect the spontaneity of the ideas in the student composition and may restrict their language use, as well as teacher's direct corrections and marks on the paper. Conversely, common observation is that students feel at ease when they interact with their peers rather than the perceived authority of the teachers. Hence, it is important to provide a seemed to be comfortable and learning opportunities which recognize individual efforts for self-improvement. That is even error correction can be an encouragement for students to view errors as an opportunity for learning the target language. 


\section{IRJE | Indonesian Research Journal in Education | | Vol. 5 | No. 1|June | Year 2021|}

Nevertheless, given the increased emphasis on student-centered instruction and the reservation of teacher's role in the classroom as facilitator of learning, for communicative language learning (CLL), L2 learning is a collaborative activity where the learner is actually participating in the process. With the introduction of peer editing as another scheme, students can have a personal encounter with their errors with less imposition from the teacher's direct correction. According to Wood (2017), peer editing has several merits which include students' interaction enables them of teaching each other at the same time. This as he further reiterates can improve their self-concept and be comfortable with the second or foreign language. Each student takes a negotiating role to contribute and to receive as well. In fact, it is believed that text improvement during a writing activity should be done in much freer condition of peer collaborative activity. Hence, this study attempted to describe the effect of peer editing in improving student's composition. The results gained from the study described the revision priorities, types, and extent of revision of peer editing. Specifically, the study tried to explore what lexical items are revised first in peer editing activity, what types of revision are employed in peer editing activity, and to what extent, in terms of over-all quality are the texts revised in peer editing activity.

\section{Literature Review}

Learner's language contains errors (Kinsella \& Singleton, 2011). That is, some of the utterances produced by the learners are not well formed according to the rules of the adult grammar. However, errors are important source of information about language use and language learning because they can conclusively demonstrate that learners do not simply memorize the target language and its rules, they reproduce the language in their utterance; they explore the language and try to invent it (Santos, 2019; Falla-Wood, 2017). The exploration and expression of the language are integral components of second language (L2) acquisition in the macro skills such as in writing.

In their discussion of accommodation and restructuring principles in language use, Abedi and Sato (2007) explain the relationships of input and the established linguistic skill. According to them, the learners tend to permit new structure to their already existing structure or to restructure their existing structure based on the new input. The learners tend to permit new expressions given the input. Oftentimes however, Sato et al. (2010) say that this results in a mismatch of linguistic structure and communication purpose. Hence, during the accommodation and restructuring processes, errors are inevitable and error correction is required. This is commonly observed in writing composition in L2 and FL. In composition writing, error correction usually happens during the revision stage. Nevertheless, text editing and improvement entail error correction. General perception is that editing of students' composition is done by the teacher (Jedlowski, 2000; Mišak, et al., 2005; Barnett, 1989). Teacher editing according to them is seen on how errors are corrected, what types of errors are corrected first and who is expected to correct the errors. A review by Hendrickson (1978) cited in Uysal and Aydin (2017), Pawlak (2014) and Barnett (1989) of several foreign language education literature on error corrections reveal that (a) no current standards exist on whether when, which or how student errors should be corrected or who should correct them, (b) there are few widely accepted linguistic criteria of grammatical and lexical 


\section{IRJE | Indonesian Research Journal in Education | | Vol. 5 | No. 1|June | Year 2021|}

correction in foreign language teaching, (c) much of what has been published on error correction is speculative, and needs to be validated by a great deal of empirical experimentation, and (d) despite the limitations, a sufficient body of literature on error correction exists to merit a systematic review in the process.

In Communicative Language Learning (CLL), learning experience is considered a dynamic activity because the learner is actually participating in the process (Fella-Wood, 2017). They are learning at the same time monitoring their weaknesses and improvement. The experience becomes positive and thereby improves the self-efficacy of students in learning the language. The employment of process-product approach, according to Myles (2002) follows the same cognitive and affective learning framework for it facilitates the opportunity for knowledge building and transformation. Hence, emphasis on student-centered instruction and the teacher's role as facilitator as explained by Lim \& Griffith (2016) be considered in communicative language classroom. Specifically during the productive stages, the involvement of students in the writing process; prewriting, writing the drafts, and improving the drafts, is vital to the development of positive values towards the language learning and facilitate the learning strategies of the students (Eckstein, 2016). Hence, Chaudron (1998) emphasizes the exploration of peer correction or self-correction with teacher's guidance in empowering individual student's self-efficacy for he believes that in peer editing, students feel at ease when they interact with their peers. This self-efficacy belief of the students is vital consideration in the employment of peer editing in ESL composition class. Padilla (2002) finds significant advantages to using written peer feedback in developing students's writing skills. Accordingly, although revisions in the peer editing addressed more the grammar and sentence construction, mechanics and word choice, the student writers attended fully to the feedback given by the peer. This provided an opportunity of confidence and trust, thus "giving room for recommendations" (p. 64). Her study further reveals that the peers seemed to find convenience in explicitly correcting the essay. In turn, the student writers find it easy to substitute forms in their work for the option provided by the peer editors. The identified disadvantages, however, is that most students in peer editing dwell more on surface errors. Also, according to Zhang (2002), there are instances, however, that indirect association of some aspects of the process is used and thereby affecting the target skill. His study, for instance, found that the peer editors felt they are playing as teacher editors when they edit their classmates drafts in the manner their teacher edited they own drafts. Students at any instructional technique use linguistic modifications.

In the field of linguistics and language learning, Bertrand (2013) underscores two objectives of error correction in student compositions in terms of theoretical and practical importance. The theoretical aspect deals with the language pedagogy used inside the classroom that looks into the learning process of the students. On the other hand, the practical aspect is concerned with the remedial action to be taken to correct the needs either on the part of the learner or the teacher. Bertrand (2013) adds that the function of error analysis is both theoretical and practical as it explains eventually the sources of the errors in order to help the student writers to understand them and correct afterwards. The forms and rules for their combination are what they call the grammar of the language. Insai and Poonlarp (2017) say that all languages are rule-governed. They hypothesize that selective 


\section{IRJE | Indonesian Research Journal in Education | | Vol. 5 | No. 1|June | Year 2021|}

error correction is a more effective instruction and technique - both cognitively and affectively, in internalizing the rules in the structures. Accordingly, they considered high frequency errors to have top priority. Muthmainnah (2019) suggests that errors in general grammatical rules are more deserving of attention than errors involving lexical exceptions. Hence, she suggests that common errors that impede meanings should be corrected first. However, linguistic proficiency alone does not seem to lead to better writing (Hasibuan, 2013; Barkley et al., 2014; Philippot \& Graves, 2009; Galvis, 2010). Indeed, there is more to good writing than linguistic accuracy. Some linguists believe that one aspect to improve in student compositions is the understanding of how the language operates appropriately in the content and context. Error correction as both input and intake as a form of accommodation and restructuring processes is not just a mere rendition but an integral part of language acquisition as shown in Figure 1 below.

Figure 1. Accommodation and restructuring processes

(inputprocessing) $\quad$ (accommodation/restructuring)
Input $\longrightarrow$ intake $\longrightarrow$ developing system

Aside from the identification of error, another important aspect in peer editing is the priority of error correction (Bertrand, 2013). According to him, priority of error correction entails which structure/s or category/categories be corrected or revised first. He further explains that the priority of error correction is deemed important for it will not only help the student writers to correct errors but also will provide instructional clue of presenting lessons of structures. Research found that verbs and prepositions are most problematic in the student composition. These are followed by modifiers and pronouns; the least is the nouns.In verbs, common errors committed by the students are $\mathrm{S}-\mathrm{V}-\mathrm{A}$, time sequencing (tenses) (Nakamaru, 2010; Eckstein, 2016; Evans \& Ferris, 2019),

The strongest argument for systematic group work in text editing is that it generates spontaneous interaction between or among the members of a group, creating opportunities for the development of their emerging internal system (Yugandhar, 2015). Yugandhar (2015) explains that peer groups provide a mutually supportive environment for learners that is less threatening than the direct editing with the teacher. Rosnida and Zainal (2011) propose a language pedagogy that is based on the use of group work. They enumerated advantages of such strategy such as group work generates interactive language and at the same time offers an embracing effective climate. Also, because group work is a step toward individualized instruction, it promotes learner's responsibility and autonomy.

Figure 2. The conceptual framework showing the relationship input and output under the peer intervention

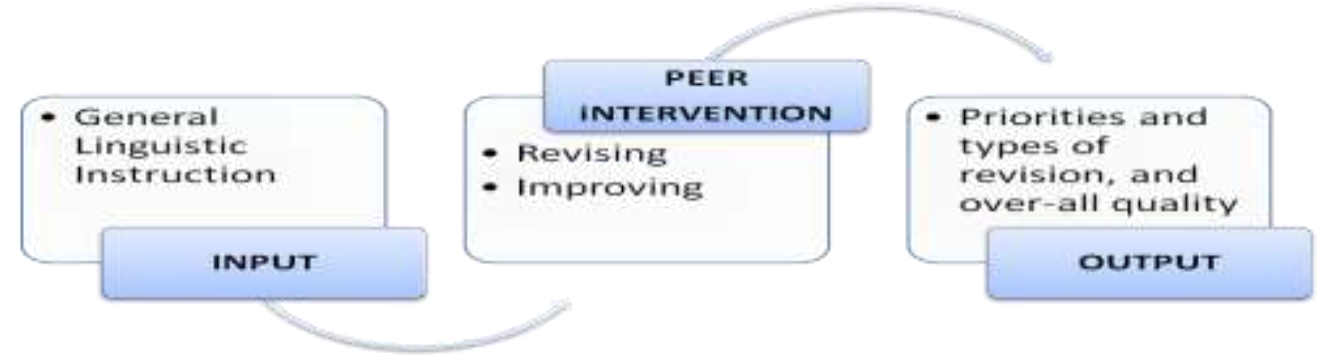

|E-ISSN: 2580-5711 |https://online-journal.unja.ac.id/index.php/irje/index | 


\section{IRJE | Indonesian Research Journal in Education | | Vol. 5 | No. 1|June | Year 2021|}

Figure 2 shows the process of accommodation and restructuring has been an integral part of text editing and text improvement. Freeman - Larsen and Long (1991) have emphasized that input is comprehensible through an interaction process where learners clarify, confirm and repeat features of L2 which they do not really understand. In the process, they somehow depend on the manner of revision and available feedback for improvement. Though these instructional modifications, linguistic adjustments such as accommodation and restructuring are provided to the improvement of organization and the comprehensibility of the texts.

A study on peer error feedback by Zheng (2007) focuses on finding the extent that the students can correct their language errors in collaboration with peers. According to him, peer editors have preferences of editing such as the local errors rather than the global errors. Specifically, peer editors focused more on a specific lexical category to edit first, like nouns first before verbs, modifiers etc. But as Zheng (2007) emphasizes, these are not errors in competency but are performance mistakes out of carelessness. Evan and Ferris (2019) report that peer editors made both text-based and surface revisions. Further, he classifies the types of revisions employed by the Japanese EFL students as (1) addition when the peer editor adds information to the paper, (2) deletion, when the peer editor deletes information, (3) substitution, when the peer editor substitute information, (4) permutation when the peer editor rephrases information, (5) distribution when the peer editor rewrites same information in larger chunks, (6) consolidation when the peer editor combine separate information together, and (7) re-order when the peer editor moves information. Finally, Bermudez \& Prater's (1994) study reveals that over-all quality of composition after the peer editing activity yielded reliability and significant relationship. Over-all quality and number of units (words, idea unit and sentences) qualify the importance of peer editing technique.

\section{Research gap}

The process approach is considered a framework for writing process. Through this, learners are able to get sufficient feedback. Studies support the idea that error correction facilitates communicative and linguistic proficiency in a target language, more than if these errors remain uncorrected. However, there is no general consensus on what categories are to correct in students drafts. Also, studies have quite a hint on when to correct these categories so as to conclusively identify how the corrections improve the drafts. Hence, it is emphasized that teachers should create a kind of classroom environment where students can confidently express their ideas, feelings, aspirations and meanings. However, as seen in the results of many studies, this is usually hindered by the perceived imposition of teacher's authority during the editing and correction process, more the embarrassment and threat of being singled out by classmates brought by errors committed during the composing stage. Though many educators propose priorities on error corrections like those errors that carry a high degree of stigma, and those seriously impair comprehension, the local errors vs. the global errors (e.g., Rivera- Mills \& Plonsky, 2007; Bitchener and Ferris, 2012; Hasan and Akhand, 2010; Hyland, 2000). Bu \& Kyo (2019), Kyle (2016), Macintyre \& Gregersen (2012), Nunan (1989), and Sheen and Ellis (2011) proposed strongly that in the productive stages teachers should directly involve the students in all the writing stages; prewriting, 


\section{IRJE | Indonesian Research Journal in Education | | Vol. 5 | No. 1|June | Year 2021|}

writing the drafts and editing and proofreading. In the editing and proofreading stage, it is encouraged to try out how students react on group editing and conferencing to lessen the impact of teacher's correction; hence, this study. Much has been found on teacher's authority in students' effort of improving their drafts, but there is a dearth of studies on peer editing.

\section{Methodology}

\section{Research design, site, and participants}

The present study is descriptive - inferential research that relied on quantitative data. As the study aimed at describing a number of features of data, this study described the frequency of the lexical items revised in peer editing, types of revision employed in peer editing and the over-all quality of the texts revised in peer editing activity. This study also employed inferential method to identify the significance of peer editing in improving the students' drafts. Hence, the quantitative data in this study were generated through text analysis of students' drafts following the text improvement process based on Figure 3. In text analysis, the text editing and text improvement process started with the teacher discussing principles of effective sentences and principles of good paragraph writing including editing and revising techniques for two weeks. This is the general linguistic input. In the revision-intervention, students took turns to read all the drafts of the group, and proofread and wrote their suggestions for improvement. In the revising activity, students incorporated the corrections and suggestions written on their paper. Finally, impressions were taken from the drafts by comparing the two drafts to answer the research questions posed earlier.

A total of 50 student participants were randomly selected from the two sections of Teacher Education programs. These students were enrolled in Writing in the Discipline (Engl 110) subject in Central Luzon State University. Their ages ranged from 16-18. The two sections, BSED and BEED, were classified as comparatively equal in academic performance based on their average rating in the qualifying examination for the program. Finally, they were considered to be of equal formal L2 background for they passed the two basic English courses, English 100 (Study and Thinking Skills) and English 105 (Oral Communication).

Figure 3. Text improvement process in peer editing

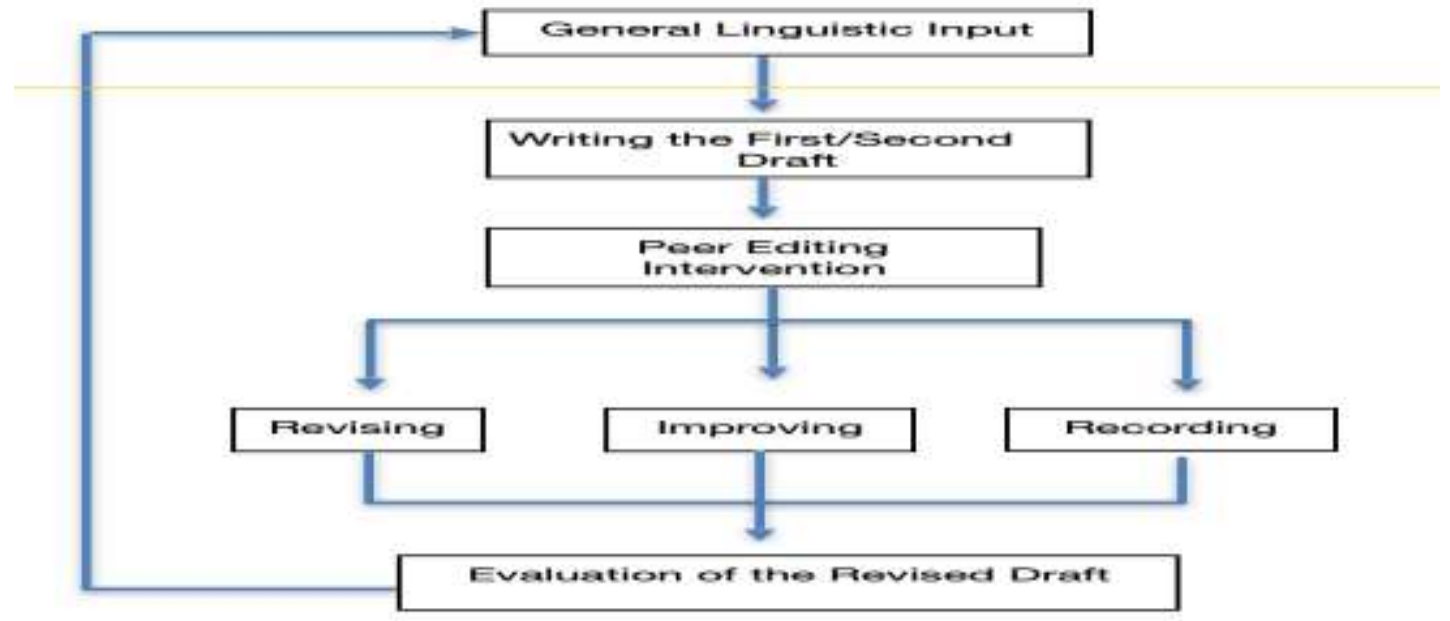

|E-ISSN: 2580-5711 |https://online-journal.unja.ac.id/index.php/irje/index | 


\section{IRJE | Indonesian Research Journal in Education | | Vol. 5 | No. 1|June | Year 2021|}

\section{Data collection and analysis}

For the text improvement process, the study was guided by the Accommodation and Restructuring Theory and on Krashen's Accommodation Theory illustrated in figure 1. Further, process - product approach was followed in the composition development as shown in figure 2. The analysis of the results led to the assessment of effectiveness of the peer editing in terms of the identified variables as a technique in improving student composition.

The text analysis covered both descriptive and inferential statistics specifically the t-test. The numerical descriptive analysis was adapted from Zeng (2007) covering the frequency of revision on linguistic categories, and the types of revision such as addition, deletion, substitution, permutation, distribution, consolidation and re-order following Nakanishi (2007). Following Prater and Bermudez's (1993), numerical analysis was used to present the means and standard deviation and the t-test between the first and final drafts so as to gain impressions on the significant difference between the two drafts for overall quality, word, sentences and idea units. The overall quality is based on a six-point holistic scoring scheme. Fluency was measured by counting the number of words, sentences and idea units. An idea unit is a single clause, dependent or independent. The scoring was also validated by two inter-raters who are also teachers of the same subject in writing. The inter-rates' assessment yielded $87 \%$ similarities. Then to evaluate the difference of the two drafts in terms of the effectiveness of the editing scheme used in improving their composition, data was subjected to ANOVA at 0.05 and 0.01 levels of significance.

\section{Ethical considerations}

This research used individuals as the main source of the data. But to keep the rights of human research participants, their names and personal details were kept with utmost confidentiality. They were also told that their submission of drafts for this study was voluntary.

\section{Findings}

\section{Frequency of revisions of lexical categories}

As shown in figure 4, the frequently revised or edited words were the nouns and verbs, both in the first and second drafts. The peer editors tended to change words into their synonym or related words. It implies that the peer editors gave importance to word choice.

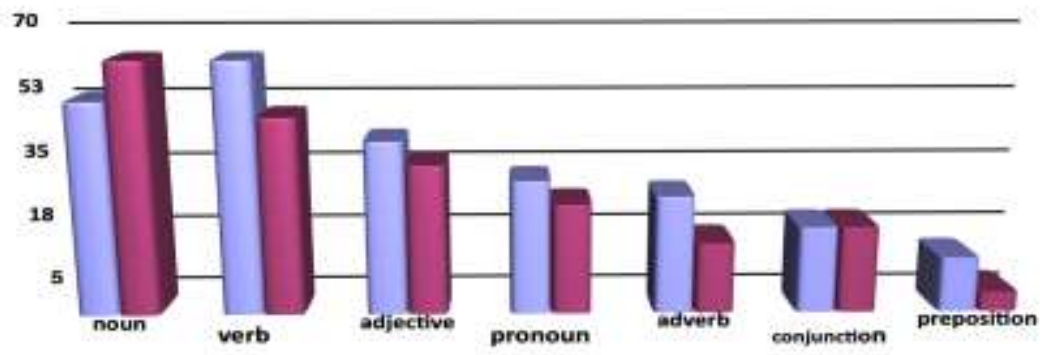




\section{IRJE | Indonesian Research Journal in Education | | Vol. 5 | No. 1|June | Year 2021|}

Figure 4 shows that in terms of revising lexical categories, the peer editors revised nouns and verbs in both first and second drafts. Data present more than half revisions on these two lexical categories. They are followed by adjectives which are at 36\% and 34\% for the first and second drafts respectively. Peer editors also revised pronouns at $30 \%$ and $24 \%$ for the first and second drafts. Following the pronouns is adverb where significant observation between the first and second drafts was deduced. Unlike other previously identified lexical categories, adverbs were revised more in the first draft than in the second draft. In fact, the conjunction which follows adverb was revised more than adverb in the second draft. Also, peer editors found it to revise conjunction equally both in the first and second drafts at $17 \%$. The least revised lexical category was the preposition. An observable decrease of frequency for the preposition was generated between the first and the second drafts, $13 \%$ and $4 \%$ respectively.

\section{Types of revisions}

In composition writing, students invest time responding to the assumptions of revision and improvement. In doing so, several linguistic responses were employed.

Table 1. Types of revisions employed in the first and second drafts

\begin{tabular}{lcccc}
\hline \multicolumn{1}{c}{ Types of Revision } & \multicolumn{2}{c}{ First Draft } & \multicolumn{2}{c}{ Second Draft } \\
\hline & $\mathrm{f}$ & $\%$ & $\mathrm{f}$ & $\%$ \\
Addition & 18 & 36.00 & 32 & 64.00 \\
Deletion & 27 & 54.00 & 16 & 32.00 \\
Substitution & 35 & 70.00 & 26 & 52.00 \\
Permutation & 13 & 26.00 & 21 & 42.00 \\
Distribution & 9 & 18.00 & 33 & 66.00 \\
Consolidation & 15 & 30.00 & 11 & 22.00 \\
Re-Order & 13 & 26.00 & 21 & 42.00 \\
\hline
\end{tabular}

Table 1 shows the types of revisions in the drafts. Multiple types were used apparently in the revision process. With the first draft, almost two thirds $(70 \%)$ of the peer editors tried to revise the text by substituting words intended to correct identified errors. These were done usually on local errors such as subject-verb-agreement, verb forms, pronoun-antecedent, and others. Further, addition registered lower $(36 \%)$ than deletion where more than half of the peer editors marked words to be omitted. Almost equally employed types of revision were consolidation $(30 \%)$, permutation $(26 \%)$, and re-order $(26 \%)$. The least employed types of revision is distribution (18\%).On the second draft, distribution, addition and substitution were employed the most, $66 \%, 64 \%$ and $58 \%$ respectively. Permutation at $42 \%$ was employed more than deletion at $32 \%$. Least employed revision functions on the second draft were re-order and consolidation, at $42 \%$ and $22 \%$ respectively. 


\section{IRJE | Indonesian Research Journal in Education | | Vol. 5 | No. 1|June | Year 2021|}

\section{Functions of revision}

Table 2 shows the different functions of revisions that are employed which include grammatical, cosmetic, texture, deletion and explicature. A significant $36 \%$ of the peer activity focused on revising the composition grammatically. The revision activities were based on the grammatical rules and conventions the peer editors have in mind.

Table 2. Functions of revisions

\begin{tabular}{lcc}
\hline Functions of Revisions & f & $\mathbf{\%}$ \\
\hline Grammatical: to make the text grammatically correct & 18 & 36 \\
Cosmetic: to improve the lay-out of the text & 4 & 8 \\
Texture: to change sentence or paragraph length for variety & 3 & 6 \\
$\begin{array}{l}\text { Deletion: to remove unnecessary and problematic information } \\
\text { Explicature: to make the information in the text more vivid and } \\
\mathrm{n}=50\end{array}$ & 11 & 22 \\
\end{tabular}

Next to grammatical function is the explicature at $28 \%$. Revision in explicature was done by making the information in the text more vivid and more direct. Following explicature is deletion, a little lower at $11 \%$. For deletion, peer editors remove unnecessary and problematic information. The two least functions of revision which were employed by the peer editors are cosmetic and texture at $8 \%$ and $6 \%$ respectively.

\section{Size of revision}

According to Hassan and Akhand (2010), size of revision is also known as fluency. Fluency is measured by counting the number of words, the number of sentences and the number of idea units in each composition. An idea unit is defined as a single clause, independent or dependent (Hasan \& Akhand, 2010).

Table 3. Size of revision done in response to the peer editing

\begin{tabular}{|c|c|c|}
\hline Size & $f$ & $\%$ \\
\hline Symbol & 3 & 6 \\
\hline Word & 12 & 24 \\
\hline Phrase & 7 & 16 \\
\hline Clause & 6 & 12 \\
\hline Sentence & 21 & 42 \\
\hline Paragraph & 2 & 4 \\
\hline $\mathrm{N}=50$ & & \\
\hline
\end{tabular}

Table 3 shows the most frequent size of revision of the drafts done by the student writers in response to the peer editing. Most of the revisions were on sentence level at $42 \%$. Sentences were either elaborated or re-ordered. Next to sentence level revision was on word level at $24 \%$. Although the student writers were concerned of making their idea explicit, they also judiciously checked their structures on the word level. Following were phrases and clauses, 


\section{IRJE | Indonesian Research Journal in Education | | Vol. 5 | No. 1|June | Year 2021|}

$14 \%$ and $12 \%$ respectively. Last revisions come from symbols and paragraph level at $6 \%$ and $4 \%$ respectively. Punctuations were confined only on the most familiar ones like period, comma, question marks and seldom quotation marks, colons and semi-colons. Lastly, paragraph revision (4\%) was done last. One paragraph was transferred from the beginning to end for the purpose of emphasis. Another one was deletion of the whole paragraph as it was felt unnecessary in the composition.

\section{Overall quality of the revised drafts}

Table 4 presents the test of significance between the first and second drafts relevant to the peer editing as an intervention to composition improvement. The variables tested are overall quality, total number of words in the composition, idea unit or the total number of comprehensible phrases in the composition, and total number of sentences.

Table 4. Test of significance between the first and second drafts

\begin{tabular}{lcccccc}
\hline Structures & \multicolumn{2}{c}{ First Draft } & \multicolumn{2}{c}{ Second Draft } & \multicolumn{2}{c}{ t-test } \\
\hline Over-all quality & Mean & SD & Mean & SD & & \\
Words & 2.88 & 0.67 & 2.58 & 10.57 & 11.583 & $0.001^{* *}$ \\
Idea Unit & 161.37 & 41.84 & 184.64 & 50.07 & 12.718 & $0.000^{* *}$ \\
Sentence & 25.57 & 6.19 & 26.57 & 6.96 & 1.153 & $0.284^{*}$ \\
\hline
\end{tabular}

In terms of over-all quality, test of significance shows that there is a highly significant difference between the first draft and the second draft. Total number of words in the composition is also found to have a high significance between the two drafts. The difference in total number of phrases referred to in this study as idea unit and the total number of sentences in the composition were found to be significant.

\section{Discussion}

Frequency of revisions of lexical categories, the frequently revised or edited words were the nouns and verbs, both in the first and second drafts. The peer editors tended to change words into their synonyms or related words. This shows that the peer editors gave importance to word choice. Also, peer editors were quite conscious of subject-verb agreement $(\mathrm{S}-\mathrm{V}-\mathrm{A})$. Many of the concerns posted relative to verbs were on $\mathrm{S}-\mathrm{V}-\mathrm{A}$. However, the specific focus on $\mathrm{S}-\mathrm{V}-\mathrm{A}$ was seen to be evident that some other forms of verbs were neglected. Revised next to nouns and verbs were adjectives, pronouns and adverbs. They were identified based on the notion of appropriate expression to match the meaning (word choice). Most of the errors identified by the peer on pronouns were agreement with its antecedent. Adjectives and adverbs were revised on the basis of what is perceived to be more appropriate term (word choice). Peer editors tended to revise adjectives and adverbs by changing the writer's words with synonymous term.

What is evident in the data is that students seemed to feel that nouns should be more specific (choice of words) while the verbs should be grammatically correct. (e.g. S-V-A, 


\section{IRJE | Indonesian Research Journal in Education | | Vol. 5 | No. 1|June | Year 2021|}

tenses). This is also in cognizant with the findings of Anudin (2019) as he states verbs in sentences are given emphasis to be structurally correct in most student composition. Verbs, together with nouns, were the ones tended to be revised in the first draft. In the students' drafts, the most difficult features of the verb were present progressive, irregular past form, regular participle, third person singular agreement, and the auxiliary verbs. The difficulty in verb was evident when the peer editors corrected the verbs in the first draft but would revise them again in the second draft. This is an indication of backsliding according to Myles (2002) and is a common occurrence in L2 writing.

Student participants also show difficulty in addressing concerns on adjectives, pronouns and adverbs. However, a limitation was observed in terms of peer editing relative to modifiers. This shows a limitation of the peer editors in dealing with errors. They saw single error at a time and thereby corrected errors one after the other too. In such cases, peer editors revised nouns but failed to check on agreement with related modifiers. With pronouns, most of the errors were on pronoun-antecedent relationship or the consistency in number and in person. This was very evident in the first drafts. This is attributed to the nature of the peer editors' L1 (Filipino) which does not specifically provides active reconstruction of consistency in number and in person. William (2012) and Berowa and Agbayani (2019) explain it as related to the role of input. As part of text improvement, conjunctions were frequently added to structures to make meaning more elaborated and exemplified. As frequently used forms of revisions were addition and expansion, peer editors believe conjunctions can help achieve such forms of revisions. Nevertheless, the students did not display common errors in conjunctions except in trying to expand the meaning. Conjunctions were often used when students tried to expand the ideas through adding more sentences, phrases and clauses.

Lastly, the least edited lexical category was prepositions. However, students' limitation on prepositions was illustrated in the process of pointing out the errors to the supposedly revision action. That even the peer editors marked the preposition to point out it needed revision, the student writer ignored it. This is attributed to the L1 - L2 non-correspondence on prepositions. Like consistency in number and person, and agreement of subject and verb, accurate use of prepositions is not represented in L1 as there is just limited number of preposition in L1 compared to much of the L2. Prepositions are indeed, one of the most difficult words to master in SLA, hence was the least word edited by the peer. Significant to note was the equal attention given by the peer editors on conjunctions in the two drafts. This can be attributed to the notion that conjunctions somehow are easy to employ for the simplicity and their constant functions (Anudin, 2019). In some instances in the students drafts, there were indications that the student writers also employed self-correction that even if it was not corrected or edited by the peer editor if he/she felt his/her sentences needed to be changed, he/she initiated the correction. This is another proof of students' empowerment and improvement of self-efficacy. While observing the process of peer editing, the student tended to monitor his/her own development and doing thing on her own.

Finally, the instances and the frequency of error correction to the different lexical categories were explained by students as simultaneous with their effort to understand and internalize the features of the target language. The process of understanding and 


\section{IRJE | Indonesian Research Journal in Education | | Vol. 5 | No. 1|June | Year 2021|}

internalizing the features of the TL was the accommodation and restructuring of the intake process in SLA. This intake process later produced the developing system of the students which became very evident in the students' second drafts. In the process of accommodating they commit over-generalization, simplification, and transfer. These categories according to Richards (2015) are student's limitation in terms of linguistic performance.

Types of revisions, in composition writing, students invest time responding to the assumptions of revision and improvement. In doing so, several linguistic responses were employed. With the first draft, majority of the peer editors tried to revise the text by substituting words intended to correct identified errors. These were done usually on local errors such as subject-verb-agreement, verb forms, pronoun-antecedent, and others. As Zheng (2007) illustrates, peer editors focus first on local errors than on global errors. Data show that peer editors' employment of substitution and deletion was attributed to the editing culture the students were exposed to. More often than not, even with teacher's editing, to edit or revise means to correct structures grammatically, and also to delete problematic structures. Also, based on the results, the attitude that the student writers have toward the peer editors and the revision strategies of improving the text they employed influenced the composition. It shows that even the students were given the freedom to work on their own in peer editing, they still tended to accomplish the task with the perceived teacher's expectation and protocols in mind. Further, addition registered a little lower than deletion where more than half of the peer editors marked words to be omitted. Still a common practice in the revision stage, peer editors seemed to think that the weakness of the composition can be addressed by adding more information. This is a usual tendency of students, that if they wanted to be understood, they offer lengthy explanations and exemplifications. Almost equally employed types of revision were consolidation, permutation, and re-order. This may be attributed to the notion of continuity of these three types; that is to rewrite same information in larger chunks is also to rephrase and to re-order the information.

On the second draft, distribution, addition and substitution were employed the most. The student writers' employment of distribution usually was done for emphasis in meaning but necessarily not following the suggestion of the peer editors for improvement. This is because the usual notion students have after the first editing was that unnecessary and problematic items in the composition were already been removed Permutation was employed more than deletion. This shows the probability that student's believed that the first draft had undergone improvement and therefore should maintain the remaining structures perceived to be necessary after the first editing. Least employed revision functions on the second draft were re-order and consolidation. Re-order and consolidation were used to simplify the idea and also to eliminate structure errors.

It is evident that on the second draft, peer editors attempted to make the composition more expressive as they required the writer to provide more information. As the first draft revision focused on local errors; the second draft revision of the peer editors focused on the idea or content of the composition. This is a relevant finding and insightful to teaching L2; peer editors focused on one concern on each stage of editing and not the wholistic concerns of improving the composition at a time. 


\section{IRJE | Indonesian Research Journal in Education | | Vol. 5 | No. 1|June | Year 2021|}

With such reactions toward the comments and suggestions of the peer editors on their texts, the student writers seemed to be relaxed and confident in the interaction process. The student writers were not somehow conscious of the ratings they got but what was more important was to express themselves and be understood. This is another proof of self-efficacy as also illustrated in Nakanishi (2017). However, there were instances in the student's reaction to the peer editing that they tried to challenge the peer editors, their classmates, whom they believed were somewhat of their own level with respect to L2. This agrees with William (2012) observations that the students did not totally trust the editing of their classmates. For instance, the students followed the revision suggested by the peer editors but they also put marks such as question marks before or after the changed word/s or underscored the edited part.

Although the student writers had a freer atmosphere in peer editing activity, the students still considered grammar accuracy which students "perceived to be an imposition in teacher-led editing" (Park, 2010:23). A significant amount of the peer activity was focused on revising the composition grammatically. This is attributed to the usual focus of editing process the students have experienced and was evident in the peer editors' comments. The peer editors were somewhat in a role as teachers. Most of their corrections were on local errors regardless whether their classmates adhered to the editing or not. Their understanding of a better composition was one of grammar accuracy. This agrees with Myles (2002) findings. This is attributed to their basic language education where correct usage of structures was emphasized (Tonio et al., 2019). In an informal interview, most of the students stated that acquiring L2 means mastering the rules of grammar. Also in consideration of the process-oriented task, the students still considered the teachers to be final and ultimate reader and editor of the composition (McGarell, 2002). Hence, although the study shows that improvement during the peer editing activity was more likely on the content of the text, both student writers and peer editors tried hard to correct grammar errors.

Next to grammatical function is the explicature. Consistent with the prior findings of Richards (2015) and Santos (2019), texts were revised to make the meaning vivid through explicature, adding, and substitution. These actions in the revised texts show that student writers did not believe that all marked parts of the composition were erroneous, but probably just a misunderstanding that they need to explicate to make their meaning come across. Another, results show that deletion was minimally used as a means of revisions. This supports the observation above that rather than delete, student writers explained more or exemplified more to make their meaning understood. Hence, they viewed the editing as not a correction to an error both on structure and content, but just a lapse of judgement of the peer editors toward the content. Also, student writers felt they own the content and the meaning. So in case word or words were marked by the peer editors, the student writers tried to maintain the idea of the structure by rephrasing or expanding the meaning. In fact, during the revision stage and rewriting the edited drafts, the student writers even approached the peer editors to clarify and explain the marked structure and convinced them that these words should not be deleted. This finding is supported by Porto (2000) who states that the writer uses his/her experience; knowledge, opinions and beliefs to own the meaning and to build 


\section{IRJE | Indonesian Research Journal in Education | | Vol. 5 | No. 1|June | Year 2021|}

his/her message in the composition. As observed, this non-deletion was an indication of the sense of equality perceived by both groups. As illustrated, because student writers did not want to delete as much as possible any part of the composition, neither did the editors often employ deletion as a revision scheme. The peer editors indirectly extended respect to the student writers toward their ownership of the content and meaning.

Size of revision, results on the size of revision show that the most frequent size of the drafts done by the student writers in response to the peer editing was on sentence. Sentences were either elaborated or re-ordered. These were done by continuous adding of sentences with less fear of being edited again. This was in support to the intention of the student writers to make their details more explicit when peer editors tried to correct their composition. Also, this shows the less inhibitions of the student writers on the editing intentions. This also proves the relaxed relationship between the student writers and the peer editors. More so, the relaxed atmosphere in the peer editing activity enabled the student writer to assert their property of the composition specifically the idea therein. When not adding another sentence to elaborate or explain the idea, the student writer tried to restate or rephrase the whole sentence. Hence, this shows the intention that the student writer would like to maintain the idea. Indeed, this direct display of strong belief to the idea is a sign of self-efficacy during the composition writing.

Next to sentence level revision was on word level. Although the student writers were concerned of making their idea explicit, they also judiciously checked their structures on the word level. Both student writers and peer editors believed that local errors should also be checked as in the case of word choice, verb form, and agreement. These were observed in the word level. This was done through substitution which was one of the most frequently employed types of revision. The manner in which revision on the word level was done and was acted upon particularly for correct usage concerns showed that the usual revision the students were exposed to. Peer editors marked the word that was supposed to be revised and the student writers just focused on the marked word. As Porto (2000) revealed in his study, although good content is valued, and flaws in content are penalized, serious grammatical mistakes are also prioritized.

Due to the complex process of writing in L2, the student writers often found it difficult to develop word groups in large chunks. In most observations, instead of revising phrases and clauses, the students tend to revise the whole sentence. They felt that ideas and structures of these phrases and clauses were not isolated from the whole sentence. Last revisions come from symbols and paragraph level. Symbols including punctuations were not much problematic to both student writers and editors. Punctuations were confined only on the most familiar ones like period, comma, question marks and seldom quotation marks, colons and semi-colons. Most of the errors in punctuation marks though was on the use of comma. As identified, student writers were prone to elaborating and expanding their ideas to an extent of committing run-on sentences. This however is in contrast with Sato et al (2010) findings that students tended to write shorter and simpler structures in their composition to avoid revisions. Lastly, paragraph revision was done last. It was not surprising that student writers revised texts on paragraph level because it entailed much effort and time to do it. Also, students believed that in revising paragraphs, they were actually revising the idea. The limited instance of paragraph revision, however, was done through re-ordering. One 


\section{IRJE | Indonesian Research Journal in Education | | Vol. 5 | No. 1|June | Year 2021|}

paragraph was transferred from the beginning to end for the purpose of emphasis. Another one was deletion of the whole paragraph as it was felt unnecessary in the composition.

Overall quality of the revised drafts, test of significance between the first and second drafts relevant to the peer editing as an intervention to composition improvement shows significant relationship. The effect of the peer editing in improving the composition was highly significant with over-all quality and number of words in the composition. This means that the peer editing activity somehow made the writer conscious of their errors in the presence or absence of the exact correction because based on the given data for revised texts; the editors seldom provided the exact correction. Frequently, the editors circled, underlined or put question mark or other devices that highlighted the part for revision. The students therefore were made conscious of their errors and took the initiative to correct them though sometimes the correction seemed still to be inappropriate or incorrect which was similar to findings of Muthmainnah (2019), Barkley et al. (2014) and Rosnida and Zainal's (2011) studies. The limitations of the peer editors were attributed to their linguistic competence as well as the lack of training for efficient editing skills. However, the high significant correlation between the peer editing and the over-all quality of the texts was a result of the writer's intention to make their ideas explicit. The idea or content of the composition improved because the writer wanted to prove to the peer editors, seen as classmates by the writers, of the worth of their text. The number of words was also highly significant with the employment of peer editing. As the editor requested the writer to improve the second draft through elaboration as a result of the distribution, permutation and addition revisions. The writers added a lot of words to explain more or to exemplify the ideas in the composition.

However, it was not significant with idea units and sentences. Results show that students at their level elaborated ideas by adding words and not much of longer structures such as idea units and sentences. Looking closely at the data, students even at the same level benefit from the peer editing activity. Generally, they adhered to the editing done by their classmates as there was a lot freer atmosphere. More importantly, the reactions given by both group, the peer editors and the student writers show establishment of self-efficacy as confidence was shown on their feedback to the editing process. This is similar to MacIntyre, and Gregersen's (2012) discussion in their study on language anxiety.

\section{Conclusions}

Based on the results of the analysis, peer editors focused on a single linguistic concern as they edited. Most of their initial editing focused on local errors such as on correct use of nouns and verbs. This has pedagogical implications. Students know that the backbone of an utterance is nouns and verbs. Teaching lexical items should be contextualized; and that these words are realized not only inside the classroom but in authentic experience of making meaning. Another, the difficulty of both groups regarding the preposition should be considered in the curricular concerns. Within the limitations of the activity, preposition somehow is neglected. Teaching the proper use of preposition should be given attention like that of other categories. 


\section{IRJE | Indonesian Research Journal in Education | | Vol. 5 | No. 1|June | Year 2021|}

Data show that the major functions of revision used by the editors were to make the information vivid and more exemplified. This is the metalinguistic characteristics of the students in terms of SLA; that to make other people to understand them is to provide elaborate and detailed explanation. This is also attributed to a freer atmosphere brought about by the peer to peer interactions. They were not inhibited by the idea that an authority, the teacher, would be reading and grading the composition. This is a classic advantage of using peer editing activity in composition development. This is student empowering and developing self-efficacy, not only of their own but collaboratively realized with their peers.

Although the student writers had a freer atmosphere in peer editing activity, the students still considered grammar accuracy which students "perceived to be an imposition in teacher-led editing" (Park, 2010, p. 23). Peer editing activity focused on revising the composition grammatically. This is attributed to the usual focus of editing process the students have experienced and was evident in the peer editors' comments. Their understanding of a better composition was one of grammar accuracy. This was attributed to their basic language education where correct usage of structures was emphasized (Santos, 2019). Hence, although the study shows that improvement during the peer editing activity was more likely on the content of the text, both student writers and peer editors tried hard to correct grammar errors. Next to grammatical function was the explicature. The actions in the revised texts show that student writers did not believe that all marked parts of the composition were erroneous, but probably just a misunderstanding that they needed to explicate to make their meaning come across. As observed, this non-deletion was an indication of the sense of equality perceived by both groups. As illustrated, because student writers did not want to delete as much as possible any part of the composition, neither did the editors often employed deletion as a revision scheme. The peer editors indirectly showed respect to the student writers of their ownership of the content and meaning.

More so, the relaxed atmosphere in the peer editing activity enabled the student writer to assert their property of the composition specifically the idea therein. When not adding another sentence to elaborate or explain the idea, the student writer tried to restate or rephrase the whole sentence. Indeed, this direct display of strong belief to the idea was a sign of self-efficacy during the composition writing. Next, although the student writers were concerned of making their idea explicit, they also judiciously checked their structures on the word level. Both student writers and peer editors believe that local errors should also be checked as in the case of word choice, verb form, and agreement. This was done through substitution which was one of the most frequently employed type of revision. Last revisions were symbols and paragraph. Punctuations were confined only on the most familiar ones like period, comma, question marks and seldom quotation marks, colons and semi-colons. Most of the errors in punctuation marks though were on the use of comma. As identified, student writers were prone to elaborating and expanding their ideas to an extent of committing run-on sentences. Lastly, paragraph revision was done least. It was not surprising that student writers revised texts on paragraph level because it entailed much effort and time to do it. Also, students believed that in revising paragraphs, they were actually revising the idea.

In terms of over-all quality, based on the correlation analysis, the effect of the peer editing in improving the composition was highly significant with over-all quality and number of words in the composition. This means that the peer editing activity somehow made the 


\section{IRJE | Indonesian Research Journal in Education | | Vol. 5 | No. 1|June | Year 2021|}

writer conscious of their errors in the presence or absence of the exact correction for the editors seldom provided the exact correction. Frequently, the editors circled, underlined or put question mark or other devices that highlighted the part for revision. However, the highly significant correlation between the peer editing and the over-all quality of the texts was a result of the writer's intention to make their ideas explicit. The idea or content of the composition improved because the writer wanted to prove to the peer editors, seen as classmates by the writers, of the worth of their text. The number of words was also highly significant with the employment of peer editing. As the editor requested the writer to improve the second draft through elaboration as a result of the distribution, permutation and addition revisions. However, results show that students at their level elaborated ideas by adding words and not much of longer structures such as idea units and sentences.

In general, students even at the same level benefit from the peer editing activity, foremost because it was done on a lot freer atmosphere. More importantly, the reactions given by both group, the editors and the writers show establishment of self-efficacy as confidence was shown on their second drafts as output of the editing process.

\section{Disclosure Statement}

No potential conflict of interest was reported by the authors of this manuscript.

\section{References}

Abedi, J ., \& Sato, E. (2007). Linguistic modification. In LEP Partnership ( Isue Brief No. 17, pp. 53-72). Retrieved from http://www.ncela.gwu.edu/files/uploads/11/abedi sato.pdf

Anudin, A. (2019). The use and overuse of transitional conjuncts in written Asian Englishes. The Asian EFL Journal, 25(5.1), 453 - 477.

Barkley, E. F., Cross, K. P., \& Major, C. H. (2014). Collaborative learning techniques: A handbook for college faculty. New York: John Wiley \& Sons.

Barnett, M. A. (1989). Writing as a process. The French Review, 63(1), 31-44.

Bermúdez, A. B., \& Prater, D. L. (1994). Examining the effects of gender and second language proficiency on Hispanic writers' persuasive discourse. Bilingual Research Journal, 18(3-4), 47-62.

Berowa, A.M.C., \& Agbayani, R.S. (2019). The MTBMLE policy attitudes among teachers on the ground. The Asian EFL Journal, 21(12.3), 123 -141.

Bertrand, B. J. (2013). Peer editing in composition for multilingual writers at the college level. Research in the Teaching of English, 54(2), 161-180.

Biber, D., Nekrasova, T., \& Horn, B. (2011). The effectiveness of feedback for L1-English and L2-writing development: A meta-analysis. ETS Research Report Series, 2011(1), i-99.

Bitchener, H., \& Ferris, D. (2012). Written corrective feedback in second language acquisition and writing studies. Language Teaching, 45(4), 446-459.

Bui, G., \& Kong, A. (2019). Metacognitive instruction for peer review interaction in L2 writing. Journal of Writing Research, 11(2).

Chaudron, C. (2003). 22 Data Collection in SLA Research. The handbook of second language acquisition, 762. 


\section{IRJE | Indonesian Research Journal in Education | | Vol. 5 | No. 1|June | Year 2021|}

Eckstein, G. (2016). Grammar correction in the writing centre: Expectations and experiences of monolingual and multilingual writers. Canadian Modern Language Review, 72(3), 360-382.

Evans, K., \& Ferris, D. (2019). Revision from multiple feedback sources: The attitudes and behaviors of three multilingual student writers. Research in the Teaching of English, 54(2), 131-160.

Falla-Wood, M. (2017). Errors in second/foreign language learning and their interpretations. Education and Linguistics Research, 3(1), 1-7.

Galvis, N. M. D. (2010). Peer editing: A strategic source in EFL students 'writing process. Colombian Applied Linguistics Journal, 12(1), 85-98.

Hasan, M. K., \& Akhand, M. M. (2010). Approaches to writing in EFL/ESL context: Balancing product and process in writing class at tertiary level. Journal of NELTA, 15(1-2), 77-88.

Hasibuan, K. (2013). Teaching writing as productive Skills. Journal of English and Arabic Language Teaching, 4(2), 169-190.

Hendrickson, J. M. (1978). Error correction in foreign language teaching: Recent theory, research, and practice. Modern language journal, 62(8), 387-398.

Hyland, K. (2003). Genre-based pedagogies: A social response to process. Journal of second language writing, 12(1), 17-29.

Insai, S., \& Poonlarp, T. (2017). More Heads Are Better than One: Peer Editing in a Translation Classroom of EFL Learners. PASAA: Journal of Language Teaching and Learning in Thailand, 54, 82-107.

Jedlowski, S. M. (2000). The effects of a teacher editor, peer editing, and serving as a peer editor on elementary students' self-editing behavior. (Doctoral dissertation, ProQuest Information \& Learning).

Kinsella, C., \& Singleton, D. (2014). Much more than age. Applied Linguistics, 35(4), 441-462.

Kyle, K. (2016). Measuring syntactic development in L2 writing: Fine grained indices of syntactic complexity and usage-based indices of syntactic sophistication. [Doctoral dissertation, Georgia State University. https://scholarworks.gsu.edu/alesl diss/35

Larsen-Freeman, D. (2011). A complexity theory approach to second language development/acquisition. New York: Routledge.

Leki, I. (1991). Twenty-five years of contrastive rhetoric: Text analysis and writing pedagogies. Tesol Quarterly, 25(1), 123-143.

Lim, H., \& Griffith, W. (2016). Developing intercultural communicative competence in foreign language learning. Sociology and Anthropology, 4(11), 1030-1035.

Ludemann, P. M., \& McMakin, D. (2014). Perceived helpfulness of peer editing activities: First-year students' views and writing performance outcomes. Psychology Learning \& Teaching, 13(2), 129-136. https://doi.org/10.2304/plat.2014.13.2.129

MacIntyre, P., \& Gregersen, T. (2012). Affect: The role of language anxiety and other emotions in language learning. In Psychology for language learning (pp. 103-118). Palgrave Macmillan, London.

Mišak, A., Marušić, M., \& Marušić, A. (2005). Manuscript editing as a way of teaching academic writing: Experience from a small scientific journal. Journal of Second Language Writing, 14(2), 122-131. 


\section{IRJE | Indonesian Research Journal in Education | | Vol. 5 | No. 1|June | Year 2021|}

Muthmainnah, N. (2019). Optimizing Critical Thinking Skill Through Peer editing technique in Teaching Writing. ELTIN JOURNAL, Journal of English Language Teaching in Indonesia, 7(1), 1-7.

Myles, J. (2002). Second language writing and research: The writing process and error analysis in student texts. Tesl-Ej, 6(2), 1-20.

Nakamaru, S. (2010). Lexical issues in writing center tutorials with international and US-educated multilingual writers. Journal of Second Language Writing, 19(2), 95-113.

Nakanishi, C. (2007). The effects of different types of feedback on revision. Journal of Asia TEFL, 4(4).

Nelson, M., \& Carlson, H. (2006). Incorporating Peer Feedback in ESL Classroom: Learning through Reflection. In Frontiers of Language and Teaching, Vol. 2: Proceedings of the 2006 International Online Language Conference (IOLC 2006) (p. 455). Universal-Publishers.

Nunan, D. (1989). Closing the gap between learning and instruction. Tesol Quarterly, 29(1), 133-158.

Nunan, D., \& Richards, J. C. (Eds.). (2015). Language learning beyond the classroom. Routledge.

Padilla, A. M. (2006). Second Language Learning: Issues in Research and Teaching.

Paltridge, B. (2014). Genre and second-language academic writing. Language Teaching, 47(3), 303.

Park, K. (2012). Learner-corpus interaction: A locus of microgenesis in corpus-assisted L2 writing. Applied Linguistics, 33(4), 361-385.

Pawlak, M. (2014). Error correction in the foreign language classroom reconsidering the issues. Springer.

Philippot, R., \& Graves, M. F. (2009). Fostering comprehension in English classes: Beyond the basics. Guilford Press.

Prater, D., \& Bermudez, A. (1993). Using peer response groups with limited english proficient writers. Bilingual Research Journal, 17(1-2), 99-116.

Rivera-Mills, S. V., \& Plonsky, L. (2007). Empowering students with language learning strategies: A critical review of current issues. Foreign Language Annals, 40(3), 535-548.

Rosnida, A., \& Zainal, I. Z. (2011). Peer editing practice in the writing classroom: Benefits and drawbacks. ALLS, 2(1), 92-93.

Santos, M. (2019). Analysis of the grammatical construction and compositionality of verbal problems: Linguistics and logic interface in the mathematics language. Asian EFL Journal, 24(4.2), 37.

Sato, E., Rabinowitz, S., Gallagher, C., \& Huang, C.-W. (2010). Accommodations for English language learner students: the effect of linguistic modification of math test item sets. (NCEE 2009-4079). Washington, DC: National Center for Education Evaluation and Regional Assistance, Institute of Education Sciences, U.S. Department of Education.

Selinker, L., \& Candlin, C. (Eds.). (1992). Rediscovering Interlanguage. England: Longman Group Uk Ltd.

Sheen, Y. (2010). Differential effects of oral and written corrective feedback in the ESL classroom. Studies in second language acquisition, 32(2),203-234.

Sheen, Y., \& Ellis, R. (2011). Corrective feedback in language teaching. Handbook of research in second language teaching and learning, 2, 593-610. 


\section{IRJE | Indonesian Research Journal in Education | | Vol. 5 | No. 1|June | Year 2021|}

Singleton, D. (Ed.). (2011). Second language acquisition: Lexical errors and accuracy in foreign language writing. Great Britain: MPG Books Group.

Tonio, JZ., Anudin, AG., \& Lucas, RI. (2019). Lexical features and motivations of product reviews on selected philippine online shops. Asian EFL Journal, 24(4.2), 161-190.

Uysal, N. D., \& Aydin, S. (2017). Foreign Language Teachers' Perceptions of Error Correction in Speaking Classes: A Qualitative Study. The Qualitative Report, 22(1), 123-135.

Weeks, J. O., \& White, M. B. (1982). Peer editing versus teacher editing: Does it make a difference? Urbana, IL: National Council of Teachers of English.

Williams, J. (2012). The potential role(s) of writing in second language development, Journal of Second Language Writing, 21(4), 321-331.

Wood, J. F. (2017). Errors in second/foreign language learning and their interpretations. Education and Linguistics Research, 3(1), 1-14.

Yugandhar, K. (2015). Practicing teacher organized peer review to Advance EFL students, writing skills. International Journal on Studies in English Language and Literature, 3(1), 25-29.

Zheng, Y. (2016). The complex, dynamic development of L2 lexical use: A longitudinal study on Chinese learners of English. System, 56, 40-53.

Zhang, Y. (2007). Analysis of Using Multimodal Feedback in Writing Instruction from EFL Learners' Perspective. English Language and Literature Studies, 8(4), 21-29.

\section{Biographical note}

MYLA LAGMAY SANTOS pursued a doctoral degree in Applied Linguistics at the De La Salle University Manila, where she also obtained her MA in English Language Education degree both under CHED Scholarship Grant. She is a faculty member of the College of Education, Central Luzon State University, Science City of Munoz, Nueva Ecija, teaching professional education courses and English major subjects in both undergraduate and graduate levels. She is also a student teaching supervisor and the former Chair of the Department of Secondary Education and the Head of Print Resources and Publication Services (PRPS) of the Center for Educational Resources and Development (CERDS), the production and publication arm of the University. She authored and co-authored references in professional education subjects and a skill text in Developmental Reading I. Her research line includes cross discipline linguistic description, syntax, and sociolinguistics. 